\section{Solitary cecal ulceration causing hematochezia}

Abhijeet Yadav, Joseph D. Feuerstein

Department of Medicine and Division of Gastroenterology, Beth Israel Deaconess Medical Center, Harvard Medical

School, Boston, MA, USA

\section{Description}

A 62-year-old male with a past medical history including morbid obesity, diabetes, and prior diverticulosis, presented with 3 episodes bright red blood per rectum. He denied any weight loss, fevers, chills, nausea or vomiting. He was taking $81 \mathrm{mg}$ of aspirin daily but no other nonsteroidal antiinflammatory medication, blood thinner or anticoagulant. He had no family history of inflammatory bowel disease or cancer. His hematocrit fell from 36.9 to 30.8 . He had a colonoscopy which showed a large solitary cecal ulceration encompassing the majority of the cecum (Figure 1A). Biopsies showed active inflammation but no chronic changes. In follow-up colonoscopies, the previously noted cecal ulcer had completely healed (Figure 1B,C). In over 4 years of follow-up since then, he has not had a recurrence of the cecal ulcer.
Correspondence: Joseph D. Feuerstein, Department of Medicine and Division of Gastroenterology, Beth Israel Deaconess Medical Center, Harvard Medical School, 110 Francis St $8 \mathrm{E}$ Gastroenterology Boston MA 02215, USA.

Tel.: +1.617.667.2136 - Fax: +1.617.667.5826.

E-mail: jfeuerst@bidmc.harvard.edu

Key words: Lower GI bleed; Solitary cecal ulcer; Colonoscopy.

Contributions: the authors contributed equally.

Conflict of interest: the authors declare no potential conflict of interest.

Received for publication: 15 July 2017. Accepted for publication: 28 August 2017.

This work is licensed under a Creative Commons Attribution NonCommercial 4.0 License (CC BY-NC 4.0).

(C) Copyright A. Yadav and J.D. Feuerstein, 2017 Licensee PAGEPress, Italy

Gastroenterology Insights 2017; 8:7313 doi:10.4081/gi.2017.7313
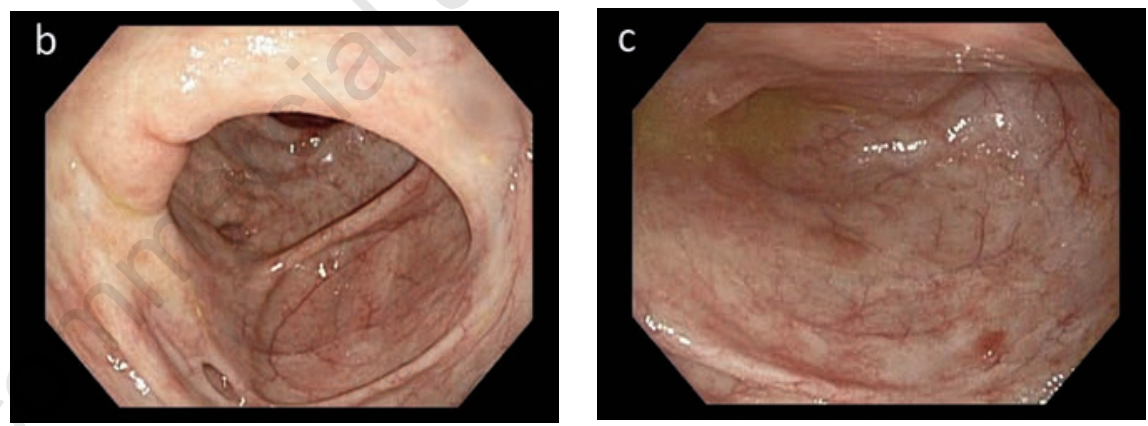

Figure 1. A) Large cecal ulceration; B) healed ulcer at ileo-cecal valve; C) healed cecal ulcer. 